\title{
PARAÍSO DAS CRIANÇAS: O KINDERGARTEN NOS ESTADOS UNIDOS ENTRE MEADOS DO SÉCULO 19 E INÍCIO DO 20
}

DOI: http://dx.doi.org/10.1590/2236-3459/56596

\author{
Carla Simone Chamon \\ Centro Federal de Educação Tecnológica de Minas Gerais, Brasil.
}

$\cos 80$

\begin{abstract}
Resumo
O objetivo deste artigo é analisar a difusão do kindergarten nos Estados Unidos, instituição educativa direcionada para crianças entre três e sete anos, concebida por Froebel (1782-1852) na Alemanha. Apesar de ter nascido na Europa, o kindergarten se expandiu nos Estados Unidos a partir da segunda metade do século 19, onde adquiriu feições próprias. É esse movimento de difusão e de americanização do kindergarten que será analisado aqui. De um lado vamos analisar as razões da aceitação do kindergarten nos Estados Unidos, buscando pelo processo de adaptação dessa instituição à cultura norte-americana. De outro lado vamos examinar, a partir de algumas obras de defensores do kindergarten, as propostas e princípios que marcaram sua implantação no referido país.

Palavras-chave: kindergarten, froebelianismo, americanização.
\end{abstract}

\section{THE PARADISE OF CHILDREN: THE KINDERGARTEN IN THE UNITED STATES BETWEEN THE MIDDLE OF 19 CENTURY AND THE BEGINNING OF THE 20}

\begin{abstract}
The aim of this paper is to analyze the spread of kindergarten in the United States, educational institution directed to children between three and seven years, conceived by Froebel (1782-1852) in Germany. Although it was born in Europe, the kindergarten had expanded in the United States, from the second half of the nineteenth century, where acquired its own features. It's this diffusion movement and this Americanization of the kindergarten which will be analyzed here. On the one hand, let us analyze the reasons for the acceptance of the kindergarten in that country, searching for its adaptation to the American culture. On the other hand, let us examine, from some works of kindergarten advocates, proposals and principles that marked its implantation in the United States. Key-words: kindergarten, froebelianismo, americanization.
\end{abstract}




\title{
EL PARAÍSO DE LOS NIÑOS: EL KINDERGARTEN EN LOS ESTADOS UNIDOS ENTRE MEDIADOS DEL SIGLO 19 Y COMIENZO DEL 20
}

\begin{abstract}
Resumen
El objetivo de este trabajo es analizar la propagación del kindergarten en los Estados Unidos, institución educativa dirigida a niños de entre tres y siete años, diseñada por Froebel (1782-1852), en Alemania. Aunque nació en Europa, el kindergarten se ha expandido en los Estados Unidos, a partir de la segunda mitad del siglo 19, donde adquirió sus propias características. Es este movimiento de difusion y de americanización del kindergarten que será analizado aquí. Por un lado, vamos a analizar los motivos de la aceptación del kindergarten allí, buscando el movimento de adaptación de esta institución a la cultura estadounidense. Por otra parte, vamos a examinar, a partir de algunas obras de los defensores del kindergarten, propuestas y principios que marcaron su implantación en los Estados Unidos.

Palabras clave: kindergarten, froebelianismo, americanización.
\end{abstract}

\section{LE PARADIS DES ENFANTS: LE KINDERGARTEN AUX ÉTATS-UNIS ENTRE LE MILIEU DU 19 SIÈCLE ET LE DEBUT DU 20}

\section{Résumé}

Le but de cet article est d'analyser la propagation du kindergarten aux États-Unis, établissement d'enseignement s'adressant aux enfants entre trois et sept ans, conçu par Froebel (1782-1852), en Allemagne. Bien que né en Europe, le kindergarten s'est étendu aux États-Unis, à partir de la seconde moitié du 19 e siècle, où il a acquis ses propres caractéristiques. C'est ce mouvement de diffusion et d'américanisation du kindergarten qui sera analysé ici. D'une part, nous allons analyser les raisons de l'acceptation du kindergarten aux États-Unis, en appuyant notre recherche sur le processus d'adaptation de cette institution à la culture américaine. D'autre part, nous examinerons, à partir de certaines œuvres des défenseurs de kindergarten, les propositions et principes qui ont marqué son implantation aux États-Unis.

Mots-clé: kindergarten, froebelianisme, américanisation. 


\section{Introdução}

$\mathrm{O}$ kindergarten, ou jardim da criança, instituição educativa direcionada para crianças em fase pré-escolar, foi concebido por Friedrich Froebel, na Alemanha, no segundo quartel do século 19. Fortemente influenciado por Pestalozzi e partindo do princípio de que a essência do processo educativo estava em desenvolver as potencialidades infantis, tanto intelectuais, quanto físicas e morais, Froebel estudou o desenvolvimento infantil, estabelecendo, a partir daí, uma proposta educacional cujo princípio básico era o de que a educação deveria se organizar de acordo com os interesses e necessidades da criança, razão porque jogos e brinquedos seriam as atividades mais naturais e educativas para elas.

Apesar de nascido na Europa, o kindergarten cresceu e se expandiu nos Estados Unidos a partir da segunda metade do século 19. Nesse país, como em outros lugares por onde se difundiu, o kindergarten se recontextualizou e ganhou novos contornos. Os primeiros kindergartens foram levados para os Estados Unidos na década de 1850 por imigrantes alemães e lá se difundiram rapidamente, estimulados tanto por uma identificação com os princípios basilares das instituições norte-americanas, quanto por se transformar numa proposta capaz de amenizar os crescentes problemas urbanos pelos quais passavam os Estados Unidos.

Esse processo de difusão não se fez sem tensões. Havia disputa entre os educadores norte-americanos a respeito do emprego da pedagogia desenvolvida por Froebel, chamada de froebelianismo. De um lado estavam os que acreditavam na necessidade de seguir de perto as instruções de Froebel, insistindo na fidelidade e na aderência aos seus princípios e métodos. De outro estavam aqueles que percebiam uma rigidez muito grande na aplicação das atividades e nos materiais propostos, acusando os primeiros de excessiva identificação com a cultura germânica. Para esses educadores era necessário flexibilizar e laicizar a pedagogia de Froebel, americanizando o kindergarten. Do confronto entre essas duas tendências podemos perceber um duplo movimento: o surgimento de um kindergarten americanizado e uma influência marcante dos princípios básicos dessa instituição na teoria educacional norte-americana produzida em fins do século 19 e início do 20. Movimento que ganhou maior visibilidade com a entrada de Stanley Hall e John Dewey no debate sobre a educação infantil e com as críticas e revisões que eles realizaram na teoria froebeliana do kindergarten.

É esse processo de implantação e americanização do kindergarten nos Estados Unidos que será analisado neste artigo. Em diálogo com a historiografia norte-americana sobre o tema o que se pretende é captar um movimento mais amplo, analisando as possíveis razões da aceitação dessa instituição no referido país, buscando também pelo movimento de sua adaptação à cultura norte-americana e as tensões que the são subjacentes. Para isso nos apoiaremos nas análises de Allen (1988) e Beatty (2000), que convergem com a nossa preocupação em compreender as marchas e contramarchas da americanização do kindergarten ${ }^{1}$. Da historiografia nacional nos apoiaremos no trabalho de Abbud (2007), cuja análise da participação de John Dewey no debate sobre a educação infantil traz importantes reflexões sobre esse processo. Examinaremos ainda

\footnotetext{
${ }^{1}$ Utilizaremos também os trabalhos de Vandewalker (1908) e Ross (1976), matizando uma certa visão natural e evolutiva do processo de implantação do kindergarten nos Estados Unidos que eles apresentam com as análises de Allen (1988), Beatty (2000) e Abbud (2007), que adotam uma postura mais crítica, evidenciado a heterogeniedade e os embates nesse processo. 
algumas obras de defensores do kindergarten, buscando pelas propostas e princípios que marcaram sua implantação nos Estados Unidos. Utilizaremos os escritos de Maria KrausBoelte e John Kraus, publicados no último quartel do século 19, especialmente o manual The kindergarten guide (1877). Eles foram dois dos principais representantes da corrente dos seguidores de Frobel nos Estados Unidos e tiveram papel destacado na difusão dessa instituição naquele país, tendo sido responsáveis pela formação de um grande número de professoras nos métodos de Froebel, sendo, por isso, fundamentais para a compreensão do que circulava nos Estados Unidos sobre o kindergarten.

\section{A aceitação do kindergarten nos Estados Unidos: aproximações}

A ideia do kindergarten, ou jardim da criança, com seus métodos e princípios, foi originalmente concebida pelo pedagogo alemão Friedrich Froebel, entre as décadas de 1830 e 1840. Baseado numa interpretação idealista do universo e do homem e fazendo ecoar as ideias de Rousseau, Froebel afirmava que as crianças eram essencialmente boas e que o processo educativo consistia em desenvolver suas potencialidades, tanto intelectuais, quanto físicas e morais. Baseava-se no princípio de que a educação infantil, ao contrário do que acontecia na sua época, deveria se organizar em torno dos interesses e das necessidades da criança e que, por isso, jogos e brinquedos seriam as atividades mais naturais e educativas para elas. A centralidade que a criança ganhava em sua pedagogia se assentava no entendimento da criança como ser criativo e produtivo e não simplesmente receptivo. Por isso, por meio dos brinquedos, do envolvimento com atividades práticas e construindo as coisas por ela mesma, a criança desenvolveria sua criatividade, se tornaria consciente de seu lugar no mundo como ser produtivo, desenvolvendo também o sentimento de cooperação com os outros.

A partir dessas premissas Froebel dividia o processo educacional das crianças em estágios de acordo com o desenvolvimento físico e mental, sendo que para cada estágio corresponderia um material específico e uma série de atividades manuais, os chamados dons e ocupações, rigorosamente ordenados, além de histórias morais, de jogos, de canções e conversações. Essas atividades, segundo seus defensores, respeitavam a liberdade da criança, oferecendo-Ihes oportunidade para desenvolver habilidades manuais e de expressão, ensinando-lhes também geometria, estética, relacionamento social e com a natureza (Kraus, Kraus-Boelte, 1877; Woolons, 2000).

O contato com a prática educacional do pedagogo suíço Johann Heinrich Pestalozzi muito contribuiu para o desenvolvimento dos métodos froebelianos. Admirador de seus princípios pedagógicos, especialmente a ênfase na prática da observação, do aprendizado por meio de objetos e da criança como ser ativo, Froebel desenvolveu sua pedagogia enfatizando o último aspecto. No entanto, diferentemente de Pestalozzi, a filosofia educacional de Froebel era perpassada de religiosidade (Hailmann, 1873; Kraus, Kraus-Boelte, 1877; Ross, 1976; Kulhmann Jr., 1998). Para ele toda a vida estaria baseada na chamada lei da unidade, da união de todas as coisas vivas, sendo Deus não só a origem de todas as coisas, mas a fonte suprema de toda a unidade e a própria Unidade. A educação teria como finalidade levar o homem a reconhecer o espírito divino que habitaria todas as coisas, tornando o ser humano consciente "do fato de que o homem e a natureza procedem de Deus e são condicionados por Ele" (Froebel, 1892, p. 5). A centralidade da dimensão religiosa conformou e significou os métodos inspirados em 
Froebel, cujo objetivo era despertar a consciência infantil para as verdades divinas, expondo as crianças a brinquedos que simbolizavam a conexão do individuo com o todo e a relação entre diversidade e harmonia. A partir de uma educação que promovesse o desenvolvimento físico, moral e intelectual, as crianças deveriam ser levadas a apreciar Deus e a manifestar sua essência divina por meio da observação, da reflexão, da atividade e da cooperação.

A princípio Froebel endereçou seu método às mães, consideradas por ele como educadoras naturais da infância, sendo capazes de desenvolver o coração, o intelecto e as mãos das crianças nos primeiros anos de vida. Assim como Pestalozzi considerava que o instinto maternal faria dela a figura ideal para se ocupar da educação da criança até os sete anos. Entretanto, Froebel percebeu não só a necessidade de auxiliar as mães nessa tarefa, mas também de se criar um ambiente favorável para essa educação, uma vez que, para ele, o ambiente doméstico seria marcado por uma atitude indulgente dos pais e fomentaria o individualismo excessivo nas crianças (Ross, 1976; Allen, 1988; Kulhmann Jr, 1998). Por isso e acreditando que antes da idade dos sete anos as crianças estavam muito novas para serem enviadas à escola, em 1839, Froebel concebeu o kindergarten, no qual as crianças experimentariam um ambiente mais regulado e cooperativo. Nele as crianças de três a seis anos de idade permaneceriam por três horas sob os cuidados de uma mãe assistente, chamada pelo pedagogo alemão de kindergartner, ou jardineira, desenvolvendo principalmente a percepção, a observação, a atenção, as faculdades artísticas e o uso coloquial da linguagem (Peabody, 1885, p. v) ${ }^{2}$.

O kindergarten foi defendido na Alemanha, tanto por grupos liberais, quanto por socialistas. Entretanto, em 1851 foi banido pelo governo, acusado de ateísmo e subversão política, em virtude de sua visão religiosa pouco ortodoxa e por estimular o trabalho feminino fora do lar (Allen, 1988). Rejeitado na Alemanha, o kindergarten foi levado para os Estados Unidos por educadores liberais alemães que para lá imigraram fugindo do fracasso da revolução de 1848. Nas cidades onde se estabeleceram buscaram preservar sua língua, sua cultura, bem como os métodos de Froebel para a educação infantil $^{3}$ (Vandewalker, 1908; Beatty, 2000). Segundo Vandewalker (1908, p. 13), até a década de 1870 haviam onze kindergartens nos Estados Unidos. Todos eles, à exceção de $u^{4}{ }^{4}$, estabelecidos por educadores alemães que utilizavam a língua e a cultura alemã como base das atividades com as crianças.

A princípio o kindergarten foi visto com reservas pelos norte-americanos em virtude da identificação com a cultura germânica e da ausência do ensino da leitura. Além disso, o valor das concepções pedagógicas do kindergarten - a criança como centro do processo educativo; como ser criativo e produtivo e não meramente receptivo; a importância da auto-expressão; o aprender fazendo - não foi rapidamente reconhecido (Beatty, 2000). A

\footnotetext{
${ }^{2}$ O kindergarten foi concebido por Froebel como espaço de educação das crianças anterior à sua entrada na escola e também como espaço de educação das mães, com cursos para que elas pudessem educar seus filhos em casa.

${ }^{3}$ Fato que confirmaria a avaliação do próprio Froebel que apostava nos Estados Unidos como o país no qual o seu sistema seria melhor recebido, em virtude do "espírito de liberdade" e "verdadeiro cristianismo" experimentados ali (Hailmann, 1892, p. 20).

4 Trata-se do kindergarten dirigido pela norte-americana Elizabeth Palmer Peadbody, aberto em Boston em 1860 (Ross, 1976, p. 2). 
esses fatores Abbud (2007, p. 41) acrescenta que haveria também, por parte do público norte-americano, o entendimento de que a família era o centro da educação infantil, o que seria um obstáculo à sua expansão.

Entretanto, aos poucos e apesar da resistência, o kindergarten foi ganhando adeptos entre os educadores norte-americanos e na década de 1880 os jardins froebelianos se faziam presentes em pelo menos trinta Estados, contando com mais de 400 estabelecimentos (Vandewalker, 1908, p. 23). Já em 1914 a maior parte das escolas públicas urbanas dos Estados Unidos havia incorporado o kindergarten ao seu sistema de ensino, adotando os princípios froebelianos também no ensino elementar.

A razão dessa aceitação pode ser explicada pela influência do idealismo entre os intelectuais norte-americanos, especialmente após a Guerra Civil, período em que houve a expansão do kindergarten nos Estados Unidos. Segundo Butts and Cremin (1953), Fichte, Schelling e Hegel foram populares nos departamentos americanos de filosofia, não sendo exagerado dizer que o idealismo se tornou a perspectiva mais influente e ensinada nas faculdades e universidades dos Estados Unidos no final do século 19 e início do seculo $20^{5}$. A concepção idealista do mundo e do homem foi fundamental para a compreensão das propostas educacionais que defendiam o respeito ao ser e à personalidade e que se preocupavam em fornecer as melhores condições para 0 desenvolvimento da natureza espiritual da criança, pressupostos subjacentes das teorias pedagógicas de Pestalozzi e Froebel.

Acrescente-se que a aceitação do kindergarten nos Estados Unidos também deve ser compreendida a partir da identificação dos princípios dessa instituição com os valores da cultura norte-americana, notadamente com o liberalismo. A proposta de Froebel era reformar não apenas a educação pré-escolar, mas também, por meio desta, a família. Para isso Froebel aproximou a pedagogia de Pestalozzi, endereçada às mães, da filosofia do idealista alemão Johann Fichte, que via a educação como um meio de regeneração da nação e de promoção de uma nova geração de cidadãos (Allen, 1988, p. 25). Froebel combinou os métodos de educação materna de Pestalozzi com o nacionalismo de Fichte e concebeu o kindergarten como uma instituição que enfatizava as virtudes públicas do cidadão e as virtudes privadas expressas no cuidado materno.

Os princípios basilares do kindergarten provocariam a superação da dicotomia público/privado, na qual se inclui a divisão casa/escola, implicando na transferência dos valores públicos para o interior da família. Por sua vez a sua defesa de uma disciplina maternal e de uma ética cooperativa, levariam os valores da esfera privada para dentro da escola ${ }^{6}$. Assim, se nos Estados Unidos, como em outros lugares, houve resistência e controvérsia à educação da criança pequena fora do lar, a atitude favorável de muitas

\footnotetext{
${ }^{5}$ Segundo Warde (2002), na segunda metade do século 19, havia uma prática de leituras hegelianas nos Estados Unidos, promovidas por imigrantes alemães. The philosophy of history, de Hegel, cuja primeira edição em inglês data de 1857, circulou entre os ambientes intelectuais norte-americanos, tendo se tornado leitura obrigatória para os hegelianos e os pragmatistas daquele país.

${ }^{6}$ Segundo Allen (1988, p. 24), essa nova relação entre a família e a escola, que o kindergarten estabelecia, demandava uma relação mais flexível entre esfera pública e esfera privada, característica de sociedades liberais como a que se configurava nos Estados Unidos naquele momento. Sociedades conservadores, como a alemã, tenderiam a enfatizar virtudes privadas como "piedade, profundidade e deferência, mantendo uma rígida fronteira entre público e privado". Sociedade liberais, ao contrário, tenderiam a uma abertura da esfera privada para as virtudes públicas como "sociabilidade, cidadania e responsabilidade social". Dentro dessa argumentação, o conservadorismo da sociedade alemã e a rigidez entre as esferas públicas e privadas teriam sido o principal obstáculo para o crescimento do kindergarten na Alemanha. 
autoridades políticas, religiosas e educacionais em relação do kindergarten podia ser considerada como derivadas do entendimento de uma ordem social baseada mais nas virtudes públicas de cidadania do que nas virtudes privadas familiares. A remoção da criança pequena de casa - lugar frequentemente identificado com indulgência e individualismo excessivo - para uma atmosfera mais regulada e cooperativa como a do kindergarten foi, pouco a pouco, sendo elaborada na sociedade norte-americana como benéfica para a preservação da ordem pública.

Essa concepção de uma relação mais flexível entre público/privado da sociedade liberal norte-americana é o que permite, segundo Allen (1988), compreender a aceitação nos Estados Unidos não só dos objetivos do kindergarten de valorização das virtudes públicas, mas também a defesa de Froebel da interferência pública na educação familiar, do kindergarten como tarefa feminina, da aplicação das qualidades maternais no contexto de uma instituição pública. Essas características encontraram terreno fértil numa sociedade em que as fronteiras entre público e privado não eram tão rígidas e "a integridade da estrutura familiar" não dependia "da preservação da fronteira público/privado" (Allen, 1988, p. 48).

Tendo essa questão como pano de fundo outros fatores contribuíram para a aceitação e rápida expansão do kindergarten nos Estados Unidos, com destaque para a necessidade de assimilação de uma crescente população imigrante e para a acolhida que a filosofia transcendentalista de Froebel encontrou entre as igrejas, particularmente as protestantes, impregnadas de valores liberais ${ }^{7}$. O aumento da imigração, o rápido crescimento das cidades e das áreas de pobreza fizeram com que muitas igrejas e sociedades filantrópicas organizassem kindergartens, vistos como meio de salvar moralmente as crianças das famílias pobres (Vandewalker, 1908; Ross, 1976; Beatty, 2000).

As igrejas protestantes, um dos principais agentes de difusão do kindergarten nos Estados Unidos $^{8}$, de maneira geral, se identificaram com a filosofia froebeliana, tanto no que diz respeito à ideia da criança como ser essencialmente bom ${ }^{9}$, quanto com relação à ênfase que o homem e a natureza eram essencialmente divinos, procediam de Deus e deveriam manifestá-lo em sua existência (Allen, 1988). Essa ênfase fez com que a ideia de desenvolvimento espiritual da criança defendida por Froebel fosse acolhida nas igrejas. Segundo Vandewalker (1908), as interpretações correntes do cristianismo ressaltavam que o homem era a maior expressão da presença de Deus, que a humanidade estava fundada numa ordem moral e que, como fruto da sua redenção, o homem se encontrava num processo de aperfeiçoamento constante. Essa visão trazia um maior senso de fraternidade humana e de obrigação social, carregando também a convicção de que a vinda do Reino de Deus dependia do homem e das agências que ele podia operacionalizar.

\footnotetext{
${ }^{7}$ Para Weber (1989), o protestantismo inglês e norte-americano se caracterizam por uma fé racional e uma aproximação com os valores liberais, sendo uma espécie de versão religiosa dos ideais do mundo moderno, baseada na idéia de liberdade e na ética da responsabilidade do homem.

${ }^{8}$ A esse respeito, Vandewalker (1908) destaca que os líderes do movimento de expansão do kindergarten, nos Estados Unidos eram todos religiosos.

9 No século 19, diferentemente dos protestantes alemães, os norte-americanos já haviam abandonado a doutrina da criança como um ser naturalmente depravado, advogando que ela seria um ser puro e naturalmente bom, o que vinha ao encontro da concepção romântica do kindergarten (Allen, 1988, p. 35). 
Nesse sentido, o kindergarten incorporou-se ao trabalho das igrejas protestantes norte-americanas como agência de salvação moral da infância. Essas igrejas o adotaram com entusiasmo como parte da missão de redimir as crianças pobres, especialmente imigrantes, e integrá-las à vida americana. Trabalho filantrópico, na maioria das vezes, a educação entre três e sete anos, que até as décadas de 1880 e 1890 praticamente não era abarcada pelo sistema público escolar, era ótima oportunidade para atuação dessas igrejas: além de formar o caráter cristão das crianças, ensinando-lhes valores morais e espirituais, afastando-as da criminalidade, traria também as suas famílias para a esfera de influência da Igreja (Vandewalker, 1908; Ross, 1976; Beatty, 2000).

Aliado a esse fator, o fenômeno da urbanização e da industrialização crescente nos anos de 1870 e 1880, levou a expansão dos objetivos originais do kindergarten. Às críticas elaboradas por Froebel às famílias das classes médias se somaram as preocupações com as famílias de classes operárias. A necessidade de assimilar uma população imigrante que aumentava a cada dia prontificou muitos educadores norteamericanos a defender uma saída precoce da criança de casa para ser educada no kindergarten, visto como uma instituição que permitiria erradicar a perniciosa influência privada por meio do ensino das virtudes públicas (Allen, 1988). Assim, ao lado dos kindergartens privados, adotado pelas famílias de classe média que apostavam na educação precoce, foram estabelecidos os kindergartens caritativos que passaram a se preocupar com a americanização e a socialização dos filhos dos imigrantes pobres.

Além disso, há que se apontar para o crescimento da aplicação da Psicologia do desenvolvimento infantil na educação. Nos Estados Unidos, especialmente a partir do final do século 19, período que corresponde à difusão do kindergarten naquele país, os estudos da Psicologia passaram a enfatizar existência de uma ordem natural no desenvolvimento da criança e a necessidade de se relacionar essa ordem aos processos e métodos educacionais. Essa Nova Psicologia e a teoria educacional que dela derivou permitiu uma aproximação e melhor compreensão dos métodos e objetivos do kindergarten, dando-lhes nova interpretação e significado mais amplo.

Nesse movimento de expansão e de aproximação da filosofia froebeliana com a cultura norte-americana, o kindergarten também teve que perder sua identificação com a cultura germânica e se americanizar, processo que não se fez sem conflitos e sem tensões.

\section{Os discípulos de Froebel chegam à America}

O movimento de difusão do kindergarten nos Estados Unidos é dividido pela historiografia norte-americana em três fases: a primeira, entre as décadas de 1850 e 1870, quando ele foi introduzido no referido país por educadores alemães que procuravam reproduzir o mais fielmente possível os métodos de Froebel; a segunda, entre 1880 e 1890, quando a expansão dos kindergartens caritativos, os free kindergartens, começou a promover uma americanização dos métodos froebelianos, e uma terceira fase, entre os anos de 1890 e a Primeira Guerra Mundial, quando ele foi incorporado às escolas públicas norte-americanas (Vandewalker, 1908; Ross, 1976; Beatty, 2000).

O primeiro kindergarten aberto nos Estados Unidos teria sido o de Margareth Shurz (Winsconsin, 1855). A ela se seguiram outros alemães que chegaram à América na expectativa de encontrar nos Estados Unidos uma terra fértil para desenvolver a 
metodologia educacional froebeliana. Nesses primeiros kindergartens havia uma forte identificação com a cultura germânica, sendo o alemão a língua na qual se educavam as crianças. Além disso a literatura sobre sua metodologia era também em língua alemã, o que dificultava a sua difusão.

As poucas experiências dirigidas por norte-americanos surgidas nesse momento reproduziam muito de perto a prática dos kindergartens germânicos, como foi o caso de Elizabeth Peabody. Considerada uma das primeiras norte-americanas a propagar os métodos inspirados em Froebel, Peabody teria aberto o primeiro kindergarten de língua inglesa em Boston em 1860 e, por meio de periódicos e conferências, influenciado outros educadores nos Estados Unidos (Vandewalker, 1908; Beatty, 2000). Nesses kindergartens, apesar da utilização da língua inglesa e do uso de canções e histórias norte-americanas, havia, como nos germânicos, uma adesão rigorosa às instruções de Froebel.

A partir do final da década de 1860 os froebelianistas norte-americanos começaram a publicar guias e periódicos com o objetivo de difundir fielmente os princípios e as orientações de Froebel. Além de periódicos, como Kindergarten Messenger, escrito e publicado por Elizabeth Peabody, a partir de 1873, e de livros e traduções como os de William Hailmann ${ }^{10}$, dois importantes guias possibilitaram a difusão da teoria e da prática do kindergarten: o guia de Edward Wiebé The paradise of childhood, publicado em Springfield, Massachussets, em $1869^{11}$, e o de Maria Kraus-Boelte ${ }^{12}$ e John Kraus's Kindergarten guide, publicado em dois volumes, em Nova York, em 1877. O objetivo dessas publicações era dar um completo entendimento da pedagogia de Froebel, mostrando o profundo significado do brinquedo para a criança e o verdadeiro espírito da sua utilização.

Segundo Wiebé (1869) e Kraus e Kraus-Boelte (1877), Froebel defendia que o processo de socialização das crianças deveria ser conduzido por atividades estruturadas e pré-determinadas realizadas com materiais geométricos que levavam as crianças a descobrir a harmonia e a simetria da vida. Por isso, o método que desenvolveu para o kindergarten incluía o trabalho com uma série padronizada de atividades lúdicas - os chamados dons e ocupações - aos quais se acrescentavam as cantigas, as histórias e as conversações.

O primeiro dom era uma caixinha, com seis bolas - três de cores primárias e três de cores secundárias -, que daria à criança ideias de forma, posição, movimento, direção, cor, peso, densidade e volume. O segundo dom era formado por uma coleção de sólidos

${ }^{10}$ Hailmann (1836-1920) foi um dos importantes defensores da Educação Nova nos Estados Unidos na segunda metade do século 19. Foi integrante da primeira associação nacional norte-americana organizada para divulgar a pedagogia do kindergarten, a American Froebel Union. Além de autor de vários livros e traduções sobre a teoria e a prática de Froebel (Ross, 1976, p. 10; Vandewalker, 1908, p. 13).

${ }^{11}$ Edward Wiebé foi professor de música nos Estados Unidos e escreveu seu manual a partir da compilação de vários manuais germânicos sobre o kindergarten (Vandewalker, 1908, p. 35).

${ }^{12}$ Maria Kraus-Boelte (1836-1918), reconhecida como uma das importantes difusoras do kindergarten, estudou a teoria e a prática do kindergarten em Hamburgo com a viúva de Froebel. Em 1872, imigrou para os Estados Unidos e no ano seguinte, juntamente com seu marido o professor John Kraus, também especialista em kindergarten e membro do Comitê de Educação dos Estados Unidos, abriu, em Nova York, uma instituição destinada a formar professoras, o chamado New York Seminary for Kindergarteners with a Model Kindergarten. Além de formar professoras, o casal se ocupou da difusão do kindergarten também em artigos de jornais, em conferências e por meio do seu manual - The Kindergarten Guide escrito em 1877 (Chamon, 2008). 
geométricos - uma esfera, um cubo, um cilindro e um cone - que introduziriam a análise e a comparação das formas. O terceiro, o quarto, o quinto e o sexto dons eram cubos de madeira divididos gradualmente e de diversos modos, por meio dos quais as crianças conheceriam o interior das coisas. A partir do sétimo dom começaria a preparação para os exercícios de abstração com as tabuinhas quebradas e triangulares, que representavam superfícies. O oitavo e o nono dons eram as réguas ligadas e as varinhas soltas, que fariam a transição entre a superfície e as linhas. O décimo e o décimo primeiro dons consistiam em palitos de madeira, anéis ou círculos e semicírculos que familiarizariam a criança com noções de aritmética, geometria e desenho. Entre as ocupações, estavam os trabalhos com papel picado, papel dobrado, entrelaçado e cortado, o desenho, a modelagem, entre outros, por meio dos quais a criança educaria as mãos, desenvolveria sua inteligência com explicações geométricas e elevaria seus sentimentos artísticos com a intervenção das formas de simetria. Arranjados numa sequência lógica e pré-determinada, dons e ocupações deveriam ser desenvolvidos numa ordem considerada pelos froebelianistas como perfeitamente natural.

Além da apresentação minuciosa dos dons e da sua utilização padronizada, esses manuais procuravam explicar o que era o kindergarten, defender a sua filosofia e os seus princípios pedagógicos. Em seu The kindergarten guide, Maria Kraus-Boelte e JohnKraus, defendiam que o kindergarten não era uma escola no sentido corrente do termo, mas funcionava como uma instituição que deveria anteceder a entrada da criança na escola propriamente dita. Funcionando por três ou quatro horas diárias, respeitando as leis naturais do desenvolvimento infantil e com uma metodologia própria, o kindergarten seria um lugar com uma atmosfera favorável para desenvolver o potencial individual e as aptidões naturais de cada criança, nos seus aspectos físico, intelectual e moral. Insistindo na importância da educação coletiva sobre uma educação isolada, os autores defendiam o kindergarten como espaço propiciador da socialização e da cooperação por meio de uma ação harmoniosa entre as crianças: "uma criança constrói os muros de uma cidade, uma outra a igreja, uma outra um monumento, uma outra a câmara municipal, uma outra a estação de ferroviária, outras casas, ruas, etc." Essa ação "individual e concertada" daria auto-confiança às crianças, desenvolveria a critividade e os valores da vida social, ensinando que os homens têm interesses em comum uns com os outros e com toda a humanidade (Kraus, Kraus-Boelte, 1877, vol.1, p. 75).

Com base nos princípios da chamada Educação Nova, apropriada aos primeiros anos de vida, mas cujo princípio metodológico deveria orientar também a instrução elementar, Maria Kraus-Boelte e John Kraus resumiam assim os objetivos do kindergarten:

Desenvolver a criança e todas as suas faculdades de um modo natural, enquanto controla todas as propensões para o mal. [...] aplicar de maneira inteligente o instinto maternal, [...] associar crianças com crianças, em uma atmosfera pura em meio a arredores prazerosos e sob orientação especial, [...] proporcionar às crianças uma diversão própria e racional, fornecer-lhes brinquedos e jogos, cantar com eles, brincar com eles, - os brinquedos, jogos, músicas e brincadeiras sendo veículos de uma instrução velada. [...] promover atividade saudável das crianças; depois despertar-lhes a imaginação gradualmente para a influência do belo, do verdadeiro e do bom; estimular sua capacidade de imitação e invenção numa direção correta. [...] impedir qualquer sobrecarga sobre a energia mental e física

\begin{tabular}{|l|l|l|l|l|l|}
\hline Hist. Educ. [Online] & Porto Alegre & v. 20 & n. 48 & Jan./abr., 2016 \\
\hline
\end{tabular}


das crianças - ensinar por meio de lições sobre objetos transmitidos pelas brincadeiras mais do que pelos livros. [...] formar uma mente bem equilibrada para discernir e fazer aflorar [...] qualquer aptidão latente para aquisições intelectuais, dons artísticos e habilidades manuais. [...] preparar as crianças para a escola, equipá-las para aprender mais prontamente, semear as primeiras sementes para produzir adultos de mente sã e corpo são - bons cidadãos e verdadeiros cristãos (1877, v.1, p. 145).

Assim, o kindergarten não seria uma escola, devendo ser definido como o paraíso da infância. John Kraus (1879) chamava a atenção para o fato de que kindergarten significava, literalmente, jardim da criança, argumentando, porém, que o termo alemão garten não significava necessariamente o mesmo que o termo inglês garden, jardim de plantas, mas, sim, lugar de recreação. Para ele, kindergarten, ou jardim das crianças, além de ser uma associação feita por Froebel dos cuidados com as crianças aos cuidados com as plantas, seria também uma associação com o Jardim do Éden, lugar de beleza e prazer, no qual a humanidade teria vivido a sua infância.

O kindergarten promoveria o desenvolvimento harmônico da criança, respeitando a sua individualidade e as leis naturais de seu desenvolvimento, enfatizando a importância dos sentidos no processo de aprendizagem e da educação não só da mente, mas, principalmente, das mãos e do coração. O princípio pedagógico básico dessa nova educação praticada no kindergarten froebeliano era o do aprender fazendo - learning by doing; do it yourself: "O método de Froebel é fundado na natureza da criança. Ele não diz: 'Ouça-me!', ele diz: 'Faça você mesmo'” (Kraus, Kraus-Boelte, 1877, v. 1, p. 459).

Nessa etapa da vida não teria lugar o ensino dos conhecimentos acadêmicos, não devendo a criança ser sobrecarregada com a instrução precoce de ler, escrever e contar. Tratava-se de, por meio de jogos e brincadeiras, sistematizadas nos dons e ocupações de Froebel, ensiná-las a construir, a inventar, a se relacionar com os outros e a ajudar uns aos outros (Kraus, 1879). Uma vez que as primeiras impressões e experiências marcariam e acompanhariam o homem ao longo da vida, a infância seria o momento ideal para criar o gosto e o prazer pelas habilidades manuais, formando um indivíduo prático e produtivo, capaz de usar as mãos de maneira inteligente. Essa proposta, segundo Kraus e Kraus-Boelte, era diferente do que em geral se praticava na educação infantil, onde o ensino se baseava quase exclusivamente no aprendizado em livros: "Endereçado apenas à mente, ele ignora as mãos" (1877, final do v. 1, p. 1). Era necessário ensinar a criança a amar as ocupações manuais, esfera em que a grande maioria da humanidade está destinada a se mover, e que permitiria a transformação e o controle da natureza. Além disso, a educação no kindergarten deveria desenvolver a apreciação estética e formar o caráter da criança, controlando as tendência para o mal, criando o gosto pelo belo e pelo bem, virtudes necessárias a um bom cidadão e um verdadeiro cristão.

Apesar de Maria Kraus-Boelte ter realizado pequenas alterações no currículo do kindergarten, de forma a adaptá-lo à América, isso não implicava ainda numa revisão dos pressupostos de Froebel. A característica distintiva de seu guia, assim como de outros nesse período, era a insistência na disciplina e na fidelidade ao método do pedagogo alemão. Extensos e detalhados, de um lado, eles apresentavam os objetivos e princípios pedagógicos do kindergarten, dando visibilidade ao seu papel como ponte entre a família 
e a escola. De outro eles reiteravam que, conforme afirmava Wiebé (1869), para obter sucesso, o sistema de Froebel deveria ser adotado como um todo, sem modificações substanciais que violassem seus princípios fundamentais.

Essa preocupação com a fidelidade ao método froebeliano fez com que Maria Kraus-Boelte, antes mesmo de publicar seu The kindergarten guide, abrisse um curso de formação para professores do kindergartens na cidade de Nova York, em 1873. Denominada New York Seminary for Kindergartners with a Model Kindergarten, essa escola de Maria Kraus-Boelte oferecia à suas alunas uma sólida e extensiva formação na teoria e na prática froebeliana, tanto por meio das aulas de treinamento, training class, quanto do kindergarten modelo. Com um currículo que incluía História da Educação, Teoria e Prática dos Dons e Ocupações, Jogos, Estórias, Música, Psicologia, Jogos Maternos, Educação do Homem, Literatura e Ciências Naturais, o curso durava em média dois anos e podia ser complementado com os cursos de extensão que podiam durar até 30 semanas. O que se pretendia era dar às futuras professoras do kindergarten uma concepção da pedagogia de Froebel e um completo entendimento de seus dons e ocupações, mostrando o profundo significado do brinquedo para a criança e o "verdadeiro espírito" do seu emprego. (A Sketch, [s.d.], p. 5-7). Por essa escola passaram mais de duzentas mulheres americanas, muitas delas com papel fundamental na difusão e na abertura de kindergartens nos Estados Unidos, como foi o caso de Susan Blow, primeira aluna de Kraus-Boelte e responsável pela primeira experiência em escola pública de uma classe de kindergarten, em St. Louis, em 1873 (Harvey, 1924; Ross, 1976; Allen, 1988) ${ }^{13}$.

Segundo Beatty (2000) a fidelidade aos princípios froebelianos nesse primeiro momento foi importante para que o kindergarten se distinguisse das antigas pré-escolas, estabelecendo métodos e práticas diferentes daqueles utilizados com as crianças mais velhas nas escolas primárias e se afirmando como uma instituição diferente, como um jardim de crianças, ponto de insistência dos froebelianistas. Além disso, os manuais elaborados por educadores germânicos, imigrados para os Estados Unidos, foram importantes para a sua divulgação. Junto com a abertura de escolas para formação de jardineiras, a circulação de periódicos, a ação de associações e sua ampla divulgação em exposições nacionais e universais, especialmente na Exposição de Filadélfia, em $1876^{14}$, deram visibilidade ao kindergarten. Os princípios e métodos educacionais que eles veiculavam - a centralidade da criança, o uso do brinquedo como material educacional, o aprender fazendo, a importância da cooperação e da vida comunitária - foram apropriados e reelaborados pelos educadores norte-americanos, colaborando para a configuração de novas teorias educacionais entre fins do século 19 e início do 20.

\section{A americanização do kindergarten}

Lentamente, a partir de fins da década de 1860, os kindergartens privados foram abertos em várias cidades dos Estados Unidos, atraindo especialmente as classes

${ }^{13} \mathrm{O}$ New York Seminary for Kindergartners atraiu também educadores de outros países como foi o caso da brasileira Maria Guilhermina Loureiro de Andrade que lá estudou na década de 1880 e, regressando ao Brasil em 1887, abriu sua escola de formação de jardineiras no Rio de Janeiro (Chamon, 2008).

14 Além da Exposição de Filadélfia, em 1876, marco no processo de divulgação do kindergarten, as Exposições Universais de Chicago (1893) e Saint Louis (1904) também reuniram representantes do movimento do kindergarten dos EUA e de vários países, colaborando para a difusão de sua proposta educacional. 
médias e altas. Essa expansão foi acompanhada de conflitos e críticas às experiências germânicas ou anglo-germânicas, gerando paulatinamente adaptações no método de Froebel, de modo a americanizá-lo. Num primeiro momento as críticas se dirigiam à utilização de jogos, canções e histórias alemãs. Mas essas eram pequenas modificações que não alteravam o simbolismo do método de Froebel e das sequências previstas de atividades. Havia também o conflito com muitos pais que demandavam para seus filhos o aprendizado precoce da leitura, o que se chocava com a recusa dos froebelianistas em introduzir esse tipo de ensino no kindergarten, considerado por eles como um trabalho acadêmico prematuro e inadequado na educação da primeira infância. Esses conflitos recrudesciam à medida que aumentava o número de educadores norte-americanos adeptos do kindergarten, o que ocorreu especialmente a partir da década de 1880 .

Nesse período, os Estados Unidos conheceram um aumento significativo dos problemas urbanos, advindos de uma rápida industrialização e da imigração que se deu após o fim da Guerra Civil (1861-1865). Embora fosse um fenômeno anterior ao conflito, foi após o seu encerramento que a indústria americana recebeu um apoio sem precedentes do governo, o que resultou na elevação e contínua expansão dos patamares de produção até o final do século 19. Esse crescimento industrial fez dos Estados Unidos a terra das oportunidades, atraindo um número significativo de imigrantes. Entre 1870 e 1900 os Estados Unidos receberam mais de 20 milhões de imigrantes vindos da Europa e da Ásia, a maior parte deles empregada como mão de obra não especializada nas indústrias em expansão. Esse processo levou a um incremento da urbanização: em 1890, os Estados Unidos possuíam mais de 26 cidades com cem mil habitantes. Em 1900, em seis delas, essa população já ultrapassava a marca de um milhão (Karnal et al., 2007).

O rápido processo de urbanização e a emergência de grandes cidades se fez acompanhar de uma série de problemas, principalmente no tocante à proliferação das áreas de pobreza. No final do século 19 o aumento de cortiços e favelas, a precariedade das condições de vida e trabalho dos operários, o desemprego, as epidemias, o aumento da criminalidade e o crescimento do número de crianças soltas nas ruas, muitas vezes cometendo pequenos delitos, era uma realidade em várias cidades do país. Nesse contexto, o kindergarten passou a ser visto como uma possibilidade para alcançar famílias imigrantes e para prevenir crimes e outros problemas sociais e se popularizou com o surgimento e a multiplicação de kindergartens caritativos, os chamados free kindergartens. Destinados às crianças pobres imigrantes, eles eram organizados por sociedades filantrópicas, igrejas e reformadores sociais como forma de reagir aos efeitos do mundo urbano e industrial na vida dessas crianças (Ross, 1976; Beatty, 2000). Com a ampliação de seus objetivos e do número de estabelecimentos, as experiências se multiplicaram e várias modificações foram se introduzindo no kindergarten de maneira a adaptá-lo ao fenômeno da urbanização e da industrialização. A partir de então não foi mais possível deter a sua americanização.

Defendendo a importância da formação na primeira infância, período negligenciado pela maioria das escolas públicas, os educadores dos free kindergartens argumentavam que, nas ruas, as crianças pobres aprendiam vícios e crimes, mas no kindergarten aprenderiam honestidade e auto-controle, sendo preparadas a serem cidadãos úteis e honrados. Agência de regeneração moral e social, remédio para os problemas e os perigos da vida urbana, o kindergarten foi também visto por esses movimentos como 
forma de assimilar e americanizar os imigrantes que, a partir do último quartel do século 19, chegavam em massa aos Estados Unidos. Segundo Allen (1988) os educadores à frente dos free kindergarten partilhavam com os froebelianistas mais ortodoxos e radicais o princípio básico de que ele seria um "modelo microcósmico de um novo ideal de sociedade composta por cidadãos que conciliavam liberdade individual com responsabilidade pública" (p. 29). Entretanto, discordavam da aplicação rígida dos dons e ocupações de Froebel. Por isso, esses educadores começaram a modificar a pedagogia froebeliana, buscando atender às necessidades das famílias e das crianças imigrantes pobres. Segundo eles, os professores norte-americanos deveriam parar de seguir ao pé da letra os métodos germânicos, caso contrário, iriam matar o espírito do kindergarten (Beatty, 2000).

As críticas tecidas por esses educadores apontavam para uma rigidez muito grande na aplicação das atividades e materiais propostos, os dons e ocupações, acusando os froebelianistas de forte identificação com a cultura germânica. Para eles, era necessário flexibilizar e laicizar a pedagogia de Froebel, introduzindo jogos, histórias e canções tipicamente norte-americanos, de modo a possibilitar identificação com os valores dos Estados Unidos, permitindo também maior desenvolvimento da individualidade da criança e do professor. Além disso, defendiam um currículo baseado em atividades práticas e cotidianas, como habilidades domésticas, preferencialmente aos jogos simbólicos propostos pelo pedagogo alemão (Ross, 1976; Wollons, 2000; Beatty, 2000).

A aposta no kindergarten como agência de reforma e de integração social fez com que muitos educadores norte-americanos se aproximassem de uma maneira não dogmática do método de Froebel. Ann Bryan, diretora da Associação do Free Kindergarten de Louisville e considerada por Beatty (2000) como uma das principais responsáveis pelo processo de americanização dessa instituição, preocupou-se em desenvolver um currículo que atraísse o interesse das crianças pobres e permitisse influenciar nas atitudes e nos valores de seus ambientes de origem. Para isso, ela introduziu no currículo atividades baseadas no cotidiano das crianças em substituição aos temas froebelianos. No lugar de seguir fielmente as atividades padronizadas do método, como tecer ou ligar com pontos padrões abstratos em cartões de papel, as crianças deveriam trabalhar com representações de pratos, mesas, fornos, camas e coisas semelhantes com as quais elas estavam habituadas (Beatty, 2000, p. 48).

Acreditando no poder do kindergarten para melhorar as condições de pobreza e para americanizar os imigrantes, educadores, como Ann Bryan, puseram em prática um currículo multicultural e assimilacionista, com atividades baseadas nas experiências das crianças imigrantes residentes nos meios urbanos. Eles também adotaram concepções científicas a respeito o desenvolvimento infantil, sintonizando o método do pedagogo alemão com os novos dados da psicologia (Idem, p. 47).

Os conflitos entre aqueles que defendiam uma fidelidade maior ao froebelianismo e os que defendiam a necessidade de adaptar o método à realidade norte-americana marcaram o cenário de difusão do kindergarten nos Estados Unidos. Entretanto, traçar uma linha separando de forma evidente esses dois grupos reduz muito a realidade daquele processo. Na verdade, se havia divergências, havia também entre eles a mesma convicção de que o kindergarten era um poderoso veículo de reforma social. Além disso, mesmo os seguidores ortodoxos de Froebel não deixaram de propor alguma adaptação 
do método à cultura norte-americana, sem perder o espírito da proposta do pedagogo alemão $^{15}$. Nesse sentido não é possível falar de vitória de um grupo por outro, mas de uma apropriação ativa e criativa por parte dos educadores norte-americanos da pedagogia de Froebel postas em circulação naquele momento, seja selecionando e reforçando nessa pedagogia o que consideravam pertinente, seja alterando-lhe algumas práticas.

Há de se observar também que a teoria educacional que começava a se desenhar naquele momento, em especial na década de 1880, ancorada nos estudos da Nova Psicologia, apontava como anticientíficas algumas das ideias e das práticas adotadas no kindergarten. As críticas ao froebelianismo ortodoxo e a reformulação de seu método tiveram seu ponto alto com a aproximação do movimento do free kindergarten com as novas tendências produzidas no campo da psicologia científica e da teoria educacional, especificamente com o child study de Stanley Hall e a educação democrática de John Dewey. Dando continuidade e aprofundando as críticas que vinham sendo elaboradas à prática dos froebelianos ortodoxos e influenciados pelas experiências dos professores dos free kindergartens, esses dois intelectuais intensificaram o movimento de americanização do kindergarten (Abbud, 2007, p. 46-47). Com eles a Nova Psicologia começou a difundir uma visão científica da educação, o que levou a uma revisão na teoria e nas práticas da instituição concebida por Froebel. Nesse momento o movimento iniciado com os kindergartens caritativos urbanos na década de 1880 se aprofundou, afastando o kindergarten do froebelianismo germânico, levando-o em direção a uma pedagogia mais progressista e científica.

Stanley Hall, importante pesquisador da psicologia do desenvolvimento infantil na virada do século 19 para o 20 e um dos fundadores do movimento child study nos Estados Unidos, foi uma das forças de modernização do kindergarten. Hall creditou a Froebel o desenvolvimento de uma pedagogia baseada nos jogos e brincadeiras e nas atividades infantis, especialmente ao ar livre, concluindo a partir de suas pesquisas que as crianças que frequentavam os free kindergartens se saíam melhor nos primeiros anos do ensino elementar do que aquelas que não haviam passado por esse tipo de instituição. Para ele, Froebel soube compreender a importância da psicologia infantil e dos estágios de desenvolvimento da criança, os quais deveriam ser respeitados e levados em conta na organização educacional $^{16}$. Entretanto, criticava como anticientífica a visão froebeliana dos jogos como uma forma simbólica de expressão da verdade divina, defendendo o relaxamento das rígidas rotinas propostas por ele em favor de jogos que ensinassem habilidades para a vida comunitária. Além disso, Hall criticou a ênfase na manipulação de objetos pequenos e nos intrincados trabalhos manuais, os quais, segundo ele, poderiam causar fadiga e problemas nervosos nas crianças. Por isso, ele defendia uma reinterpretação de Froebel, eliminando o simbolismo do currículo do kindergarten e tomando como base do método o estudo da natureza da criança (Allen, 1988; Beatty, 2000; Abbud, 2007).

\footnotetext{
${ }^{15}$ Foi o caso do froebelianista Willian Hailmann, que trazia em seu livro Kindergarten culture (1873) um capítulo intitulado Adaptation of kindergarten culture to American institutions criticando uma adesão escrava aos métodos propostos (Ross, 1976, p. 70).

${ }^{16}$ Apesar das muitas críticas, Hall se considerou discípulo de Froebel, a quem ele chamou de "estrela da manhã" do movimento child-study (Ross, 1976, p. 69). Hist. Educ. [Online] Porto Alegre v. 20 
Nesse debate a entrada de John Dewey, filósofo interessado no estudo científico da criança e na sua aplicação na educação, foi também de fundamental importância. Segundo Abbud (2007), diferentemente de Stanley Hall, Dewey temperava suas críticas ao froebelianismo procurando reconhecer e enfatizar os esforços e os avanços que a pedagogia de Froebel trazia ${ }^{17}$. Segundo o jovem reformador e chefe do Departamento de Filosofia, Pedagogia e Psicologia da Universidade de Chicago, Froebel teria sido o primeiro expoente na defesa dos princípios básicos de uma educação progressista, sendo dele o mérito de desenvolver uma pedagogia baseada na atividade da criança e no entendimento do significado e do valor educacional do jogo:

A raiz de toda atividade educativa está nas atitudes e atividades instintivas, impulsivas da criança, e não na apresentação e aplicação de material externo [...] consequentemente, as mais diversas atividades espontâneas das crianças, brinquedos, jogos, mímica [...] - anteriormente ignoradas por serem triviais, fúteis ou mesmo condenáveis como perniciosas -, não só são passíveis de uso educacional, como são as pedras fundadoras do método educacional. (Dewey, 1915, p. 112)

Sendo, como pretendia Froebel, a principal tarefa da escola conduzir as crianças a uma vida cooperativa e de ajuda mútua, ensinando-as princípios e comportamentos de interdependência, os jogos e ocupações infantis seriam a melhor ferramenta para se fazer isso: por meio deles se reproduziria, para a criança, ocupações típicos de uma sociedade mais ampla. Além disso, Dewey reconheceu e destacou a validade da noção de que as crianças alcançam um conhecimento valioso por meio de atividades produtivas e criativas (Idem, p. 112).

Dewey, entretanto, advogava que o kindergarten deveria basear seu currículo não sobre verdades divinas reveladas, mas sobre as percepções terrenas fundamentadas em valores sociais de vida comunitária. Para Dewey a preferência de Froebel por brinquedos simbólicos foi porque ele não teve ao seu alcance as evidências trazidas pelos estudos da Psicologia do final do século 19. Além disso, havia também as condições sócio-políticas da Alemanha: "Ele [Froebel] não podia ver as ocupações na sala de aula como uma reprodução literal de princípios éticos da vida comunitária - esta última era frequentemente muito restritiva e automática para servir de modelo respeitável" (Dewey, 1915, p. 116).

Dewey, então, se propôs a estudar o método froebeliano do ponto de vista dos novos estudos da Psicologia, traduzindo as proposições abstratas de Froebel para a vida prática e concreta das crianças e emancipando o kindergarten da necessidade de seguir qualquer sistema prescrito, ou sequência de dons, brincadeiras ou ocupações. A

\footnotetext{
17 As críticas de Hall foram combatidas pelos froebelianistas e, na década de 1890, o debate entre esses dois grupos ficou cada vez mais acirrado, ganhando contornos pessoais entre Stanley Hall e Susan Blow, representante dos froebelianistas ortodoxos. Nesse contexto, Dewey teria atuado de forma mais diplomática, propondo atualizações do kindegarten, mas expressando sua concordância com os princípios froebelianos e defendendo a extensão dessa pedagogia para toda a vida escolar (Abbud, 2007).

${ }^{18} \mathrm{O}$ debate direto com Froebel e os froebelinistas não aparece nas primeiras edições de Education and society, publicado orginalmente em 1899. Apenas a partir da edição revista de 1915, aqui utilizada, é que Dewey inclui um capítulo sobre os princípios educacionais de Froebel e sua utilização pelos froebelianistas nos Estados Unidos.

Hist. Educ. [Online] Porto Alegr

v. 20

n. 48

Jan./abr., 2016

p. 15-33
} 
reformulação do kindergarten deveria levar em conta as leis do desenvolvimento infantil, elaboradas pela ciência moderna. Segundo Abbud (2007) as atualizações que a Nova Psicologia introduziu no método de Froebel tiveram como resultado prático o deslocamento da atenção dos supostos interesses e capacidades das crianças em geral para os interesses de grupos de crianças em particular. Além disso, levaram o kindergarten a trabalhar a espontaneidade em detrimento da ordenação prévia e rigorosa de suas atividades.

Todo esse debate e disputa em torno da pedagogia de Froebel colaborou para a produção do kindergarten numa instituição norte-americana. Certamente que esse processo não ocorreu de maneira uniforme por todo o território dos Estados Unidos, país de dimensões continentais e atravessado por inúmeras diferenças sócio-culturais. Mas, como aponta Abbud (2007, p. 47), acabou por "produzir um padrão americano de kindergarten", incumbido da tarefa de "formar as crianças numa mentalidade desejável de uma nação democrática".

\section{Considerações finais}

A proposta educacional de Froebel, que concebia o kindergarten como um modelo micro-cósmico de sociedade, baseado nos princípios de liberdade individual e responsabilidade pública, foi a base da sua aceitação nos Estados Unidos. Na filosofia dessa proposta estava a defesa de uma transcendência da fronteira tradicional publico/privado, onde os valores dessas duas esferas - família e escola, cuidado maternal e cidadania - eram tomados como complementares mais do que dicotômicos. Nesse sentido, a aceitação que o kindergarten obteve nos Estados Unidos indicia uma visão da ordem social cujo sustentáculo não está mais na mera preservação da esfera privada, mas sim, na abertura dessa esfera para os valores públicos de cidadania, responsabilidade social e assimilação. A inserção da criança pequena no kindergarten foi percebida naquele país, ainda que não sem controvérsias e resistências, como benéfica para a preservação da ordem, como um meio poderoso de educar as crianças na sua idade mais impressionável nos valores da esfera pública norte-americana.

As experiências e o debate em torno do método de Froebel - iniciado com os free kindergartens e aguçado com a entrada de elementos da child study e da educação progressista - ampliou a sua aceitação nos Estados Unidos e se fez acompanhar por sua institucionalização nas escolas públicas. A primeira experiência de classes de kindergartens em escola pública foi realizada por Susan Blow, em St. Louis, Missouri, ainda em 1873. Mas o sucesso dos free kindergartens, a promoção do kindergarten como remédio para os problemas sociais e como agência de integração social, levou a uma defesa, por parte de educadores e reformadores sociais, para sua inclusão no sistema público escolar. No final da década de 1890, muitas cidades, como Indianápolis, Boston, Chicago e Filadélfia, haviam incluído kindergartens em suas escolas públicas, e outras cidades estavam prestes a fazê-lo (Vandewalker, 1908). Por volta de 1914 as classes de kindergarten eram uma realidade na maioria dos distritos urbanos dos Estados Unidos.

A incorporação do kindergarten ao sistema público escolar fez com que seus princípios pedagógicos também fossem experimentados e defendidos para a educação elementar. Nesse sentido, a expansão do kindergarten não pode ser medida apenas pelo número de estabelecimentos desse tipo criados nos Estados Unidos. Ela incluiu também 
um processo de difusão dos seus princípios pedagógicos no ensino primário, colaborando de maneira decisiva para uma renovação dos processos educacionais nos Estados Unidos no final do século 19 e início do 20. Na verdade, a institucionalização norteamericana da pedagogia de Froebel preparou o terreno e forneceu elementos para a configuração do que se chamou na virada do século de educação nova. Os princípios básicos dessa pedagogia - a centralidade da criança, o significado do jogo, o uso do brinquedo como material educacional, o aprender fazendo, a importância da cooperação e a ideia da sala de aula como uma sociedade embrionária - estavam no âmago da teoria e da prática do kindergarten.

\section{Referências}

A SKETCH. Manuscript division: the papers of Maria Kraus-Boelte, Box 1: Correspondence. [s.I.], [s.d.]. Disponível na Biblioteca do Congresso de Washington.

ABBUD, leda. John Dewey nos debates sobre a educação infantil: Estados Unidos dos anos noventa do século 19 aos anos dez do século 20. São Paulo: PUC-SP, 2007. $126 f$. Dissertação (mestrado em Educação). Pontifícia Universidade Católica de São Paulo, Programa de Pós-Graduação em Educação.

ALLEN, Ann Taylor. Let us live with our children: kindergarten movements in Germany and United States, 1840-1914. History of Education Quaterly, v. 28, n. 1, 1988, p. 23-48.

BEATTY, Bárbara. The letter killeth: americanization and multicultural education in kindergartens in the United States, 1856-1920. In: WOLLONS, Roberta (org.). Kindergarten and cultures: the global diffusion of an idea. New Haven and London: Yale University Press, 2000, p. 42-58.

BUTTS, Robert Freeman, CREMIN, Laurance Arthur. A history of education in american culture. New York: Henry Holt and Company, 1953.

CHAMON, Carla Simone. Escolas em reforma, saberes em trânsito: a trajetória de Maria Guilhermina Loureiro de Andrade (1869-1913). Belo Horizonte: Autêntica, 2008.

DEWEY, John. The school and society. Chicago: The University of Chicago Press, 1915.

FROEBEL, Friedrich. The education of man. New York: Appleton and Company, 1892.

HAILMANN, William Nicholas. Prefácio do tradutor. In: HAILMANN, William Nicholas. The education of man. Tradução de William Hailmann. New York: Appleton and Company, 1892.

HAILMANN, William Nicholas. Kindergarten culture in the family and kindergarten: a complete sketch of Forebel's system of early education, adapted to American institutions for use of mothers and teachers. Cincinnati: Wilson Hinkle, 1873.

HARVEY, Anna K. Maria Kraus-Boelte (1836-1918). In: Pioneers of the kindergarten in America. New York and London: The Century CO., 1924, p. 75-93.

KARNAL, Leandro et al. História dos Estados Unidos: das origens ao século XXI. São Paulo: Contexto, 2007.

KRAUS, John; KRAUS-BOELTE, Maria. The kindergarten guide, an illustrated hand-book designed for the self-instruction of kindergarterns, mothers and nurses. New York: E. Steiger; London: George Philip, 1877. 
KRAUS, John. The kindergarten (Its use and abuse) in America: The Little Gem and American Kindergarten, New York, v. 5, n. 8, 1879, p. 114-115. Disponível na Biblioteca do Congresso de Washington.

KUHLMANN JUNIOR, Moysés. Infância e educação infantil: uma abordagem histórica. Porto Alegre: Mediação, 1998.

ROSS, Elizabeth Dale. The kindergarten crusade: the establishment of preschool education in the United States. Athens: Ohio University Press, 1976.

PEABODY, Elizabeth Palmer. American preface. In: FROBEL, Friedrich. The education of man. New York: A. Lovell and Company, 1885.

VANDEWALKER, Nina Catharine. The kindergarten in American education. New York: The Macmillan Company, 1908.

WARDE, Mírian Jorge. Oscar Thompson na Exposição de Saint-Louis (1904): a exhibit showing machinery for making machines. In: FREITAS, Marcos César; KUHLMANN JUNIOR, Moisés (org.). Os intelectuais na história da infância. São Paulo: Cortez, 2002, p. 409-458.

WEBER, Max. A ética protestante e o espírito do capitalismo. São Paulo: Pioneira, 1989.

WIEBÉ, Edward. The paradise of childhood. A manual for self-instruction in Frederich Froebel's educational principles and a practical guide to kinder-gartners. Springfield Mass: Milton Bradley and Company, 1869.

WOLLONS, Roberta. On the international diffusion, politics and transformation of the kindergarten. In: WOLLONS, Roberta (org.). Kindergarten and cultures: the global diffusion of an idea. New Haven and London: Yale University Press, 2000, p. 1-15.

CARLA SIMONE CHAMON é professora no Centro Federal de Educação Tecnológica de Minas Gerais e doutora em Educação pela Universidade Federal de Minas Gerais.

Endereço: Rua José Alexandre Ferreira, 145 - 31330-636 - Belo Horizonte - MG Brasil.

E-mail: carlachamon@gmail.com.

Recebido em 21 de junho de 2015.

Aceito em 22 de agosto de 2015. 